\title{
Erratum to: Asynchrony, fragmentation, and scale determine benefits of landscape heterogeneity to mobile herbivores
}

\author{
Kate R. Searle $\cdot$ N. T. Hobbs $\cdot$ Stefan T. Jaronski
}

Published online: 10 July 2010

(C) Springer-Verlag 2010

Erratum to: Oecologia (2010) 163:815-824

DOI 10.1007/s00442-010-1610-8

Unfortunately, the third author's name in the original version of this article was published incorrectly as Stefan R. Jaronski. The correct name is Stefan T. Jaronski.

The online version of the original article can be found under doi:10.1007/s00442-010-1610-8.

K. R. Searle $(\square) \cdot$ N. T. Hobbs

Natural Resource Ecology Laboratory,

Colorado State University, Fort Collins, CO 80521, USA

e-mail: krsearle@nrel.colostate.edu

S. T. Jaronski

The Northern Plains Agricultural Research Laboratory,

USDA Agricultural Research Service,

1500 N. Central Avenue, Sidney, MT 59270, USA 